www.jmscr.igmpublication.org

Impact Factor (SJIF): 6.379

Index Copernicus Value: 79.54

ISSN (e)-2347-176x ISSN (p) 2455-0450

crossrefDOI: https://dx.doi.org/10.18535/jmscr/v6i12.93

Journal Of Medical Science And Clinical Research

IGM Publication

An Official Publication of IGM Publication

\title{
Original Research Article \\ Magnitude and Outcome of Self Medication of Abortion Pills: Our Experience at a Tertiary Care Teaching Hospital
}

Authors

\section{Pradip Kumar Panigrahi, Pratibha Jena*}

Department of obstetrics and gynaecology, Institute of Medical Science and SUM Hospital, Siksha 'O' Anusandhan

Deemed to be University, Bhubaneswar

*Corresponding Author

Pratibha Jena

Assistant Professor, Department of Obstetrics and Gynaecology, IMS\&SUM Hospital, Bhubaneswar, India

Email: pratibhajena@soa.ac.in

\section{Abstracts}

Introduction: Medical end of pregnancy has been legitimized in India for more than 40 years, yet the greater part of all premature births are hazardous. Restorative fetus removal pill is well compelling in early long stretches of pregnancy. Despite all the control, it has been seen by the general public that, therapeutic premature births are to a great degree safe alternative. In any case, it is protected just when it is utilized under therapeutic supervision. Self-organization for fetus removal is exceptionally unsafe whenever disregarded or hid. Our investigation goes for discovering the extent and result of self-prescription of premature birth pills.

Material and Method: This is an imminent observational examination led in Institute Of Medical Science and SUM healing facility Bhubaneswar, Odisha from January 2017-December 2017. This investigation included aggregate 204 numbers of cases with a background marked by self prescription of mifepristone and misoprostol who exhibited to the clinic with some intricacy. The information was factually broke down.

Results: In our examination period, add up to 204 instances of ladies with a background marked by self-drug of restorative premature birth pill,presented to healing center with some intricacy. The most continuous complaintwas sporadic draining and held result of origination (54.9\%). The dominant part of patients were inside the age gathering of 20-30 yrs (66.2\%) and55.39\% cases were second gravida.63.7\% cases had taken deficient dose.Laparatomy was required in 5 cases (2.3\%).Blood transfusion was required in 45 cases(22\%).68.6\% cases required minor careful mediation like suction and clearing.

Conclusions: Medical fetus removal pill is a viable strategy for end of early pregnancy yet it is sheltered just on the off chance that it is taken under therapeutic supervision. Self prescription and over the counter (OTC) moving of these pills ought to be confined.

Keyword: restorative premature birth pill, self medicine, perilous fetus removal.

\section{Introduction}

Medicinal premature birth pills have changed the opportunity of lady in her choice for abortion ${ }^{(1)}$. Medical fetus removal implies the end of pregnancy with therapeutic fetus removal pills
(MAP) which is today exceedingly liked to careful techniques. In India 6.4 million premature births are performed yearly and $8-20 \%$ of every single maternal passing are because of dangerous fetus removal $^{(2,3)}$. According to $\mathrm{WHO}$ hazardous 
premature birth is what isn't given through affirmed offices or potentially individual ${ }^{(4)}$. WHOCCR in human proliferation, All India Institute of Medical Science in a joint effort with service of wellbeing and Family Welfare Govt of India and Indian Council Of Medical Research have arranged the rules for medicinal fetus removal in India. This rule advocates the utilization of combo-pack of 1 Tab Mifepristone (200mg) in addition to 4 tablets of Misoprostol(200 $\mu$ gm each) for end of pregnancy up to 63 days of gestation ${ }^{(5)}$. only enlisted restorative specialists (RMP) as endorsed by MTP act are approved to recommend MAP for therapeutic fetus removal. The RMP ought to approach a place affirmed by the Government for careful and crisis reinforcement if necessary. Regardless of every one of these rules MAP are generally being sold without therapeutic remedy by the scientist over the counter. Selfmedicine of these medications in India is on the ascent particularly in the rustic regions where access to restorative administrations is poor ${ }^{(6,7)}$. Such unsupervised terminations can prompt unsafe impact on the soundness of ladies.

This investigation expects to discover the greatness of self admission of MAP, its efficacy, disadvantages and the elements that lead ladies to pick such hazardous strategies for fetus removal that can risk their wellbeing.

\section{Material and Methods}

This is an imminent observational examination led in Institute Of Medical Science and SUM clinic Bhubaneswar, Odisha from January 2015December 2015.Total 204 cases were dissected in the investigation. The patients who accompanied entanglement after organization of MAP without any medicinal solution were incorporated into the examination. Point by point history with respect to demography, dose of medication consumption and gestational age at which MAP was taken were recorded. Every one of the cases was assessed for the explanation behind end and gripe at the season of affirmation. All patients were inspected and examined completely. Each case was overseen as required. The information was broke down factually.

\section{Result}

Add up to number of 204 patients inside a time of one year was incorporated into our investigation. Greatest no of patients that is $135(66.2 \%$ ) have a place with 20-30 years old gathering. just $14(6.8 \%)$ patients were unmarried.51.4\% patients were beneath registration. Our statistic profile demonstrates $55.3 \%$ cases have a place with second gravida and the 109 cases $(53.4 \%)$ took the MAP at $8-12$ wks of incubation.

Table 2 demonstrates lion's share of cases that is $63.7 \%$ (130) cases did not take the entire portion of the MAP. Table 3 demonstrates the fundamental gripe for which the patient announced and it uncovers that unpredictable draining and held results of origination is the most widely recognized introduction (54.9\%). 4 cases announced with septicaemia.

$3.9 \%$ cases did not react to the MAP. In the management(Table - 4) suction and departure was done in $140(68.6 \%)$ cases. 45 cases $(22 \%)$ cases required blood transfusion. laparatomy was done in 4cases of ectopic pregnancy because of its burst after admission of MAP.

One patient required hysterectomy due to burst uterus. $14.7 \%$ cases required recurrent therapeutic treatment.

Table-1 Demography

\begin{tabular}{|c|c|c|}
\hline Demography & $\begin{array}{c}\text { No. of Cases } \\
(N=204)\end{array}$ & $\begin{array}{c}\text { Percentage } \\
(\%)\end{array}$ \\
\hline \multicolumn{3}{|l|}{ Age } \\
\hline$<20$ years & 35 & 17.1 \\
\hline $20-30$ years & 135 & 66.1 \\
\hline $30-40$ years & 34 & 16.6 \\
\hline \multicolumn{3}{|l|}{ Marital status } \\
\hline Married & 190 & 93.1 \\
\hline Unmarried & 14 & 6.8 \\
\hline \multicolumn{3}{|l|}{ Education } \\
\hline Below matriculation & 105 & 51.4 \\
\hline Matriculate and above & 99 & 48.5 \\
\hline \multicolumn{3}{|l|}{ Gravida } \\
\hline Gravida-1 & 62 & 30.3 \\
\hline Gravida-2 & 113 & 55.3 \\
\hline Gravida- 3 and more & 29 & 14.2 \\
\hline \multicolumn{3}{|l|}{ Gestational age } \\
\hline$<8 w k$ & 68 & 33.3 \\
\hline $8-12 w k$ & 109 & 53.4 \\
\hline $12 w k$ & 27 & 13.2 \\
\hline
\end{tabular}


Table-2 Dose of Map Taken

\begin{tabular}{|l|c|c|}
\hline Dose & $\begin{array}{c}\text { No. of Patients } \\
(\mathbf{N = 2 0 4})\end{array}$ & $\begin{array}{c}\text { Percentage } \\
(\boldsymbol{\%})\end{array}$ \\
\hline Complete dose & 74 & 36.2 \\
\hline Incomplete dose & 130 & 63.7 \\
\hline
\end{tabular}

Table-3 Presenting Complain

\begin{tabular}{|l|c|c|}
\hline Complain & $\begin{array}{c}\text { No. of Patients } \\
(\mathbf{N = 2 0 4 )}\end{array}$ & Percentage (\%) \\
\hline $\begin{array}{l}\text { Irregular bleeding with } \\
\text { retained products }\end{array}$ & 112 & 54.9 \\
\hline Heavy bleeding & 62 & 30.3 \\
\hline Pain abdomen & 18 & 8.8 \\
\hline Signs of sepsis & 4 & 1.9 \\
\hline $\begin{array}{l}\text { Non expulsion of } \\
\text { products of conception }\end{array}$ & 8 & 3.9 \\
\hline
\end{tabular}

Table-4 Management

\begin{tabular}{|l|c|c|}
\hline Procedure & $\begin{array}{c}\text { No. of Patients } \\
(\mathbf{N = 2 0 4})\end{array}$ & $\begin{array}{c}\text { Percentage } \\
(\mathbf{\%})\end{array}$ \\
\hline Suction evacuation & 140 & 68.6 \\
\hline Blood transfusion & 45 & 22.0 \\
\hline Repeat medical therapy & 30 & 14.7 \\
\hline Laparotomy for ectopic & 4 & 1.9 \\
\hline $\begin{array}{l}\text { Hysterectomy for } \\
\text { rupture uterus }\end{array}$ & 1 & 0.4 \\
\hline Sepsis management & 4 & 1.9 \\
\hline
\end{tabular}

\section{Discussion}

In India MTP act was passed in 1971 to anticipate dangerous and illicit premature birth. Yet, even after quite a while there are risky abortions.2002 change to the MTP demonstration endorsed the utilization of consolidated mifepristone and misoprostol routine as lawful therapeutic strategy for end of early pregnancy. The rules for restorative premature birth in India have been set up by WHO - CCR in human proliferation, All India Institute of Medical Sciences as a team with Ministry of Health \&family Welfare, Government of India and Indian chamber of Medical Research. ${ }^{(8)}$

Just the Obstetrician and gynecologist and enlisted therapeutic professional as characterized by MTP act, can recommend the MAP and the patients ought to have the capacity to comprehend the guidelines .The patient directing in regards to the development and necessity of surgery whenever required ought to be finished. Intensive clinical examination and examination is required before recommending the MAP.MAP. However, the principle issue with the MAP is that it is accessible over the counter (OTC). The ladies of provincial region and uneducated patients are buying this pill over the counter and taking MAP with no medical supervision.

There were 204 numbers of cases in our examination out of which $51.4 \%$ cases are underneath register Majority cases are hitched (93.1\%).

In $13.2 \%$ cases MAP was utilized for premature birth after 12 wks of development.

The accessibility of MAP through scientific experts is extremely widespread in India. Studies propose that at whatever point there is an undesirable pregnancy, numerous ladies in India endeavor to end the pregnancy all alone, by acquiring MAP over the counter without a prescription $^{(9)}$.

Most regular gripe for coming to doctor's facility was unpredictable draining and held result of origination (54.9\%). Bleeding, sepsis, and medication disappointment were discovered more in ladies taking self medicine than with specialist's prescription $^{(10,11,12)}$. Disastrous conditions like burst ectopic pregnancy, cracked uterus were additionally seen in our investigation in 1.9 and $0.4 \%$ cases separately.

Consequently restorative fetus removal needs strict cautiousness and quick access to medical help to control grimness and mortality.

\section{Conclusions}

This examination being led in a therapeutic school which is a tertiary dimension healing facility, the outcome reflects just a hint of a greater challenge. Substantial scale examines are required to evaluate the weight of the issue in the general public. However, this examination can mindful us with respect to the accidental self organization of misoprostol and mifepristone and its inconvenience. To limit this issue the patients and the scientific expert should realize that MAP ought to be utilized just under medicinal supervision. 


\section{References}

1. Ulmann A. The development of mifepristone : A pharmaceutical drama in three acts.J Am Med Womens Assoc 2000;55 3 Suppl:117-20

2. Duggal R, Ramachandran V. The abortion assessment project - India: Key fi ndings and recommendations. Reprod Health Matters 2004;12 24 Suppl:122-9

3. World Health Organization. Unsafe Abortion: Global and Regional Estimates of the Incidence of Unsafe Abortion and Associated Mortality in 2003. 5th ed. Geneva: World Health Organization; 2007. p. 56

4. WHO: The prevention and management of unsafe abortions: Report of technical working group. Geneva, 1992

5. http://gujhealth.gov.in/adfwhdownload.htm

6. Santhya KG, Verma S, Induced abortion The current scenario in India. In: Jejeebhoy SJ, editor. Looking Back, Looking Forward: A Profi le of Sexual and Reproductive Health in India. Jawaharnagar, India: Rawat Publications; 2004.

7. Ganatra B, Manning V, Pallipamulla SP. Availability of medical abortion pills and the role of chemists: A study from Bihar and Jharkhand, India. Reprod Health Matters 2005;13:65-74.

8. http://ebookbrowsee.net/guidelines-formedicalabortion-in-india-doc-d134818684

9. Kumar R, Zavier AJ, Kalyanwala S, Jejeebhoy SJ. Unsuccessful prior attempts to terminate pregnancy among women seeking fi rst trimester abortion at registered facilities in Bihar and Jharkhand, India. J BiosocSci 2013;45: 205-15.

10. Ramachandar L, Pelto PJ. Medical abortion in rural Tamil Nadu, South India: A quiet transformation. Reprod Health Matters 2005;13:54-64.
11. Sharma R, Verma U, Khajuria B. Medical termination of pregnancy with mifepristone-misopristol in rural India. J ClinDiagn Res 2008;3:901-4.

12. Banerjee SK, Andersen K. Exploring the pathways of unsafe abortion in Madhya Pradesh, India. Glob Public Health 2012;7:882-96. 